\title{
ACTIVATION OF TRASS ROCK AS BLEACHING PALM OIL (CPO)
}

\author{
Laurentius Urip Widodo ${ }^{1}$, Sukirmiyadi, Siswanto and Ely Kurniati \\ University of Pembangunan Nasional "Veteran" Jawa Timur \\ Surabaya, East Java, Indonesia \\ E-mail : gerak_samodro3@yahoo.com ${ }^{1}$
}

\begin{abstract}
Trass rock is a rock originating from volcanic eruption materials which has experienced weathering. It has the similar composition as bentonite. Therefore, trass rock can also be used as raw material as a bleaching earth to substitute bentonite. In this study, a two-stage process was conducted: to do the activation process of trass rock and stage bleaching process of palm oil (CPO). In activation process, trass rock was performed by using hydrochloric acid, then trass rock was crushed until it could pass of the 200 mesh. After that, the soft rock was weighed and added to the acid solution with the ratio of: 1 : 10 with the concentration of hydrochloric acid solution $5 \mathrm{~N}$ and its activation time was 4 hours at the temperature of $105^{\circ} \mathrm{C}$. Meanwhile, for the bleaching process, at first, oil was treated with degumming and netralization process. Furthermore, oil bleaching process was carried out by adding the activated trass . Then trass was put into the oil when its temperature was reaching up to $186^{\circ} \mathrm{C}$. Heating was continued until its temperature was reaching up to $198^{\circ} \mathrm{C}$ for 45 minutes. In this activation process, it was obtained that the content of $\mathrm{SiO}_{2}$ was $37.8 \%, \mathrm{Al}_{2} \mathrm{O}_{3}$ of $4.4 \%$ and the ratio of $\mathrm{SiO}_{2} / \mathrm{Al}_{2} \mathrm{O}_{3}$ is 8.6 . In the bleaching process of palm oil (CPO), the best condition of trass addition was $4 \%$ of the oil weight, and its bleaching time was 45 minutes, the red color intensity obtained was 6.9 and yellow was 6.1 , with FFA as big as $2.13 \%$ and peroxide value was $5.45 \mathrm{meq} / \mathrm{kg}$.
\end{abstract}

Keywords: activation,trass rock, bleaching, CPO.

\section{INTRODUCTION}

Trass rock (or tuff) is a kind of rock originated taken from eruption material of volcano or volcanic sediment. Trass is formed when it becomes decayed especially that of containing andesitic composition ( Kurum, 2009). As Indonesia has so many volcanoes in all parts of it, trass can be found everywhere in a very great quantity. Up to now, trass is only known as a natural cement and it is limited as a basic/raw material and mixture of cement. Therefore, we have to think of it as another alternative of use that seems to have higher economic value. Trass is actually the blend of active aluminia and silicate from which it contains of silica amorf (Edwin, 2007). The chemical composition of trass is almost the same as that of bentonite from which contains the blend of aluminia and silicate. Therefore, trass is possible to be used as an alternative of bleaching earth basic material.

Nowadays in Indonesia, the plantation of palm is getting more and more developed. Therefore, oil making process needs bleaching earth as a bleaching media when the palm oil (CPO) is manufactured into frying oil. Up to now, bentonite is the only one thing used as a raw material in bleaching earth making. However, we have to know that later on bentonite will be used up because it is mine goods. Bentonite can be classified into two, Na-bentonite and $\mathrm{Ca}-$ bentonite. The characteristics of Na-bentonite is that it has a big content of $\mathrm{Na}^{+}$, it can expand and suspend if it is dispersed into the water. This material can not be used as a raw material of bleaching earth. Meanwhile, in Cabentonite, it has more $\mathrm{Ca}^{2+}$ and $\mathrm{Mg}^{2+}$ than $\mathrm{Na}^{+}$. The characteristics of Ca-bentonite is that its absorption power is only a little if it is dispersed into the water, it will precipitate and will not be suspended ( $\mathrm{Fu}, 2011)$. As a matter of fact that trass has the similar composition as bentonite, it can also be used as bleaching earth. Due to the fact that trass has so many impurities covering its surface, trass needs to be activated at first before being used as a bleaching earth. Some impurity components are such $\mathrm{CaO}, \mathrm{MgO}$ and $\mathrm{Fe} 2 \mathrm{O} 3$. These impurities can be reduced or even removed by acid activation. Finally, it can increase the absorption power from the trass. The mass ratio of bentonite and the volume of acid solution is 1:10 $(\mathrm{w} / \mathrm{v})($ Foleto, 2011). Acid can create new pore so that it will increase the acidity of its surface by cation substitution such as $\mathrm{Al}^{3+}, \mathrm{Fe}^{3+}$ and $\mathrm{Ca}^{2+}$ with $\mathrm{H}^{+}$(Ejikeme, 2013). The absorption power of color substance/essence of bleaching earth is because the existence of $\mathrm{Al}$ ion available in absorbent surface. Acid activation is aimed at increasing both the degree of $\mathrm{Al}_{2} \mathrm{O}_{3}$ and $\mathrm{SiO}_{2}$. This activation will then be obtained the ratio of $\mathrm{Al}_{2} \mathrm{O}_{3}$ and $\mathrm{SiO}_{2}$. The increase of $\mathrm{SiO}_{2}$ is very important because it can increase the content of Si-OH (Cylanol) on the adsorbent surface, that is trass (Makhoukhi, 2009). During the bleaching process of the dye, peroxide and other impurities are removed from the raw material of oil. Through this process, the appearance of oil product can be improved. Its color becomes clearer and its production stability might be improved (Falaras, 2000). Bleaching earth can also remove chlorophyll, carotenoids, phosphorlipids, metals. This removal can be done through adsorption only (Makhoukhi, 2009). The new pore is created from the removal of some ion such as $\mathrm{Al}^{3+}, \mathrm{Fe}^{2+}, \mathrm{Fe}^{3+}, \mathrm{Mg}^{2+}$ from the open octahedral layer at the edge of smecteet. More over, silicon ( $\mathrm{Si}$ ) is relieved from the tetrahedral layer of precipitate in the form of silica amorf with $\mathrm{H}^{+}$ion. In fact, activation process might increase the surface area and its diameter of pore from the clay. This process can absorb more pigment (Khan, 2014). Here is the chemical reaction in activation process with trass aid as follow:

Reaction of dissolving substance.

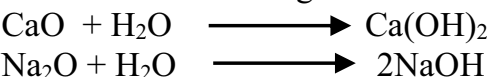


Reaction rock trass with chloride acid as the activator.

$\mathrm{Al}_{2} \mathrm{O}_{3}+6 \mathrm{HCl} \longrightarrow 2 \mathrm{AlCl}_{3}+3 \mathrm{H}_{2} \mathrm{O}$
$\mathrm{Fe}_{2} \mathrm{O}_{3}+6 \mathrm{HCl} \longrightarrow 2 \mathrm{FeCl}_{3}+3 \mathrm{H}_{2} \mathrm{O}$
$\mathrm{MgO}+2 \mathrm{HCl} \longrightarrow \mathrm{MgCl}_{2}+\mathrm{H}_{2} \mathrm{O}$
$\mathrm{CaO}+2 \mathrm{HCl} \longrightarrow 2 \mathrm{NaCl}+\mathrm{H}_{2} \mathrm{O}$

In general, the color of palm oil (CPO) before being processed, is dark red. Therefore, bleaching process needs to be done to eliminate it. To do bleaching, palm oil must be treated through pretreatment process, that is degumming and netralization. The purpose of degumming process is to remove the sap without reducing the existence of fat acid in the oil and to precipitate fosfatide which can not be soluble in the water. To do degumming process, palm oil (CPO) must be heated up to $80^{\circ} \mathrm{C}$, then added with phosphate acid of $85 \%$ as much as $0.15 \%$ from oil weight, stir within 15 minutes. The purpose of neutrallization process of palm oil (CPO) is to reduce or remove Free Fat Acid (FFA) in the palm oil. The existence of neutralization process mostly employed is using the solution of $\mathrm{NaOH}$. For netralization process, the concentration $\mathrm{NaOH}$ of solution employed was $11.1 \%$ of the weight $\left(16^{0} \mathrm{Be}\right)$ and stirred up continually within 25 minutes while being heated at the temperature of $\pm 59^{\circ} \mathrm{C}$.

The experiment was aimed at activating the trass rock so that it could be used as a bleaching earth that had much higher economic value. So far, trass rock was only used as a raw material of cement making and a mixture of concrete. The activation process of chloride acid $(\mathrm{HCl})$ was expected to obtain the bleaching earth from trass as a raw material that had a high absorption power like bentonite. Therefore, trass was used as a bleaching of palm oil (CPO) by varying the weight of trass in oil.

\section{METHODOLOGY}

The materials required in this research were trass rock, $\mathrm{HCl}$, aquades and palm oil (CPO). Meanwhile, some instruments/equipments required were iron mortar, stove/ heater, stiring tank, filter paper, funnel and oven/ dryer.

The research was carried out in two process stages, the activation process of trass rock and bleaching process of palm oil (CPO). In activation process, trass rock was crushed until smooth, then it was screened by using a screener of 200 mesh. The trass that could pass down a screener of 200 mesh was washed by using water to remove the dirt or soil attaching on the trass, then screened again and then dried up in the oven. Having been washed and dried up, activation of trass and some solution of chloride acid (with ratio 1:10) was conducted (150 gr of trass rock in $1500 \mathrm{cc}$ of acid solution). The solution concenteration of chloride acid $5 \mathrm{~N}$ with time allocation of activation process within 4 hours was heated until its temperature was reaching up to $105^{\circ} \mathrm{C}$. After that filtrating was done to separate the solid matter from the liquid. The solid matter obtained was then washed by using aquades until the $\mathrm{pH}$ of water was up to \pm 5 . Then, it (solid matter) was dried up in oven with the temperature $110^{\circ} \mathrm{C}$. The dried solid matter was then analyzed to see the content of $\mathrm{SiO}_{2}, \mathrm{Al}_{2} \mathrm{O}_{3}, \mathrm{CaO}, \mathrm{MgO}$ and $\mathrm{Fe}_{2} \mathrm{O}_{3}$ by using $\mathrm{X}$ Ray Fluorescene Mini Pal 4. Meanwhile, for the stage of bleaching process, at first oil was treated by degumming and neutralization process. In these two process, oil was heated up to $80^{\circ} \mathrm{C}$ then added with $85 \%$ of phosphate acid as much as $0.15 \%$ of the weight of oil and stirred within 15 minutes. After that the temperature was lowered up to $60^{\circ} \mathrm{C}$ and added with $\mathrm{NaOH} 11.1 \%\left(16^{0} \mathrm{Be}\right)$ as much as $2 \%$ of the volume of oil and stirred within 25 minutes. Next, oil was cooled down and refined to separate oil from the soap. The netralized oil was then bleached by adding the activated trass taken from the best activation process as much as $2 \% ; 4 \% ; 6 \%$ and $8 \%$ of oil weight. The trass was put into the oil when its temperature reached up to $186^{\circ} \mathrm{C}$ and continued up to $198^{\circ} \mathrm{C}$ as long as 45 minutes. Then this bleaching oil was analyzed its color intensity by using konicaminolta CR-10. Meanwhile, the content of FFA and peroxide was analyzed through titration.

\section{RESULT}

Based on the analysis result, it was known that the quality of trass rock before activating process as shown in the (Table-1) below:

Table- 1. Result Data of Former Trass Rock Analysis Before Activating Process

\begin{tabular}{|c|c|c|c|c|c|c|}
\hline \multirow[b]{2}{*}{ Former Material Original } & \multicolumn{5}{|c|}{ Level \% Weight } & \multirow{2}{*}{$\begin{array}{l}\text { Ratio } \\
\mathrm{SiO}_{2} \\
\mathrm{Al}_{2} \mathrm{O}_{3}\end{array}$} \\
\hline & $\mathrm{SiO}_{2}$ & $\mathrm{Al}_{2} \mathrm{O}_{3}$ & $\mathrm{Fe}_{2} \mathrm{O}_{3}$ & $\mathrm{CaO}$ & MgO & \\
\hline Before Washing & 23.4 & 3.7 & 23.8 & 27.1 & 0.5 & 6.32 \\
\hline After Washing & 19.3 & 3 & 26.9 & 26.4 & 0.5 & 6.43 \\
\hline
\end{tabular}

Meanwhile, the analysis result of trass rock after activation process using solution activator of chloride acid ( $\mathrm{HCl})$ could be seen at (Table- 2) below:

Table- 2. Result Data of Trass Rock Analysis After Activating Process with Chloride Acid (HCl)

\begin{tabular}{|c|c|c|c|c|c|c|c|}
\hline \multicolumn{2}{|c|}{ Trass Activation } & \multicolumn{5}{|c|}{ Level \% Weight } & \multirow{2}{*}{$\begin{array}{l}\text { Ratio } \\
\mathrm{SiO}_{2} \\
\mathrm{Al}_{2} \mathrm{O}_{3}\end{array}$} \\
\hline Time (Hour) & $\begin{array}{c}\text { Concentration } \\
\text { of } \mathrm{HCl}\end{array}$ & $\mathrm{SiO}_{2}$ & $\mathbf{A l}_{2} \mathrm{O}_{3}$ & $\mathrm{Fe}_{2} \mathrm{O}_{3}$ & $\mathrm{CaO}$ & MgO & \\
\hline 4 & $5 \mathrm{~N}$ & 37.8 & 4.4 & 9.38 & 20.6 & 0.6 & 8.6 \\
\hline
\end{tabular}

The following was the quantity analysis result of palm oil (CPO) before and after treatment process as shown at (Table- 3). 
Table- 3. Analysis Data of Palm Oil (CPO) Before Treatment Process

\begin{tabular}{|c|c|c|}
\hline Raw material of oil & $\begin{array}{c}\text { FFA } \\
(\mathbf{\%})\end{array}$ & $\begin{array}{c}\text { Peroxide value } \\
\text { (Meq/ Kg) }\end{array}$ \\
\hline Former oil & 3.51 & 19.90 \\
\hline Netralization oil & 2.45 & 13.95 \\
\hline
\end{tabular}

The next was the analysis result of oil after bleaching process as shown at (Table- 4).

Table- 4. Analysis Data of Palm Oil (CPO) as The Result of Bleaching Trass by HCl Activation

\begin{tabular}{|c|c|c|c|c|c|}
\hline \multirow{2}{*}{ Oil after being neutralized } & \multicolumn{2}{|c|}{ Oil Color } & $\begin{array}{c}\text { FFA } \\
(\%)\end{array}$ & $\begin{array}{c}\text { PV } \\
\text { Meq } / \mathbf{K g}\end{array}$ \\
\cline { 3 - 6 } \multicolumn{2}{|c|}{} & Red & Yellow & & \\
\cline { 3 - 6 } Bleaching Time & 7.5 & 5.9 & 2.45 & 13.95 \\
\hline \multirow{3}{*}{45 Trass Add \%Weight } & \multicolumn{2}{|c|}{ Oil Color } & $\begin{array}{c}\text { FFA } \\
(\%)\end{array}$ & $\begin{array}{c}\text { PV } \\
\text { Meq } / \mathbf{K g}\end{array}$ \\
\cline { 3 - 6 } & & Red & Yellow & & \\
\hline & 2 & 7.0 & 5.9 & 2.16 & 5.9 \\
& 4 & 6.9 & 6.1 & 2.13 & 5.45 \\
& 6 & 7.1 & 6.0 & 2.19 & 11.05 \\
& 8 & 7.3 & 5.8 & 2.37 & 12.75 \\
\hline
\end{tabular}

\section{DISCUSSION}

Natural trass rock was perhaps still mixed with soil. Therefore, it needed to be cleaned or washed before being activated. However, the washing had to be done when the size of trass particle had not been smooth or its size was about 8-10 mesh. This condition was meant to protect some required particles oftrass from removing. In this research the washing of trass rock was done after the trass rock had been shattered smoothly until it could pass the screen of 200 mesh. This might reduced the level of some required particles. (Table- 1) showed that some important particles such as $\mathrm{SiO}_{2}$ and $\mathrm{Al}_{2} \mathrm{O}_{3}$ required as a bleaching earth were removed. Before being cleaned/ washed, the level of $\mathrm{SiO}_{2}$ was $23.4 \%$ and it decreased into $19.3 \%$ after being washed. The decrease also happened in $\mathrm{Al}_{2} \mathrm{O}_{3}$. Before being cleaned, it was $3.7 \%$ and it decreased into 3\% after being cleaned. Meanwhile, the element of impurities were getting increased, $\mathrm{Fe}_{2} \mathrm{O}_{3}=23.8 \%$ became $26.9 \%$. Therefore the washing had to be done carefully and correctly, so that $\mathrm{SiO}_{2}$ and $\mathrm{Al}_{2} \mathrm{O}_{3}$ would not decreased.

Chloride acid was used as an activator in trass rock activation to removed impurities of $\mathrm{Fe}_{2} \mathrm{O}_{3}, \mathrm{CaO}$ and $\mathrm{MgO}$ available in the trass rock. The activation result showed that $\mathrm{Fe}_{2} \mathrm{O}_{3}$ element got reduced more than the others. These was due to $\mathrm{Fe}_{2} \mathrm{O}_{3}$ was very reacted to chloride acid so that during activation process, reaction mostly accured between chloride acid and $\mathrm{Fe}_{2} \mathrm{O}_{3}$. This could be seen in (Table- 2). It was known that using chloride acid as an activator could reduced impurities much available in the trass rock especially impurities of $\mathrm{Fe}_{2} \mathrm{O}_{3}$. In fact, chloride acid could decrease $\mathrm{Fe}_{2} \mathrm{O}_{3}$ up to 9.38\% from the former $\mathrm{Fe}_{2} \mathrm{O}_{3}$ in the trass rock of $26.9 \%$. In this activation process it was known that the other impurities in the trass rock did not get reduced signifycantly. This could happened because consentration of acid used as an activator was only little a before it reacted to $\mathrm{Fe}_{2} \mathrm{O}_{3}$. Therefore it could no longer reacted to $\mathrm{CaO}$ and $\mathrm{MgO}$ available in the trass rock. More over, reaction would happen to the reactive element and less reactive and then continued up to the element which was not reactive at all. The decrease of oxides was due to reaction occured inside the acid (Ejikeme, 2013). The result obtained true activation of chloride acid could be seen at (Table- 2). It was known that the level of $\mathrm{SiO}_{2}$ was $37.8 \%, \mathrm{Al}_{2} \mathrm{O}_{3}=$ $4.4 \%$ and ratio of $\mathrm{SiO}_{2}$ and $\mathrm{Al}_{2} \mathrm{O}_{3}$ was 8.6.This might cause the quantity of four was increasing If its surface was enlarged, the level of acidity would increase as an effect of structure changes (Alendaroglu, 2003). Therefore the activation of trass rock and chloride acid was considered to be good enough. The activation result of trass rock and chloride acid was then used as a bleaching of palm oil (CPO).

However before bleaching, palm oil was pretreated at first. In fact the result of this pretreatment could decrease its FFA and the quantity of peroxide available in the oil could be seen at (Table- 3). The decrease of FFA was due to its reaction with $\mathrm{NaOH}$ added during netralization process. Formerly the FFA was $3.51 \%$ and it decreased in to $2.45 \%$. This decline was only a little because the addition of $\mathrm{NaOH}$ was only $2 \%$ of the oil volume. If the quantity of $\mathrm{NaOH}$ was too much, it might cause the quantity of oil reduced. Furthermore, the result of oil bleaching employing trass as a result of activation with chloride acid could be seen at (Table- 4). It was shown that the color adsorption, FFA and the quantity decrease of peroxideoccured during the trass addition of $4 \%$ of the oil weight within 45 minutes. Moreover, before bleaching it was known that the intensity of red color was 7.5 and the yellow one was 5.9. This caused the color texture of oil tended to look red. But after bleaching process by adding the trass of $4 \%$ of the oil weight, the intensity of red color became 6.9 and the yellow became 6.1. The intensity decrease of red color and the intensity increase of yellow one made the oil texture became yellower. (Table- 4) showed that the more percentage of trass addition it did not mean that the intensity decrease of red color became higher. This was due to the adsorption balance that had already been achieved between a mixture of adsorbent and oil. This condition restrained the pigment to be adsorbed from the over dosage of adsorbent (Usman , 2013). Therefore, the more percentage of trass addition, the more increase the level FFA would be. Furthermore, 
(Table- 4) also showed the former FFA was $2.45 \%$ if it was added with trass of $4 \%$, its FFA decreased in to $2.13 \%$. Meanwhile if it was added with trass of $8 \%$, the level of FFA was $2.37 \%$. (Table- 4 ) also showed that the more percentage of trass addition the higher number the peroxide would be (Wannahari, 2012). He said that in general the used of more adsorbent did not mean to reduce the value of PV (Peroxide Value). This was due to the saturation in use of several adsorbent from which level had to be back to the limit point of adsorbent to adsorb wholly. The former peroxide value was $13.95 \mathrm{meq} / \mathrm{kg}$ and the trass addition of $4 \%$, the peroxide value decreased in to 5.45 $\mathrm{meq} / \mathrm{kg}$. Meanwhile with the trass addition of $8 \%$, the peroxide value was $12.75 \mathrm{meq} / \mathrm{kg}$. Therefore in bleaching process the higher addition of trass, it even decreased its adsorption power of trass as a bleaching earth.

\section{CONCLUSION}

The research result concluded that the washing of trass rock as the basic/ raw material should not be in smooth condition, but should be in bigger particles to maintain $\mathrm{SiO}_{2}$ and $\mathrm{Al}_{2} \mathrm{O}_{3}$ from removing. Meanwhile the activator of $\mathrm{HCl}$ with its acid concentration of $5 \mathrm{~N}$ and activation time 4 hours, it could be found that the level of $\mathrm{SiO}_{2}$ was $37.8 \%, \mathrm{Al}_{2} \mathrm{O}_{3}=4.4 \%$ and ratio of $\mathrm{SiO}_{2} / \mathrm{Al}_{2} \mathrm{O}_{3}$ was 8.6. In bleaching process, the best condition of trass addition was $4 \%$ of the oil weight with the bleaching time allocation was 45 minutes. This condition was obtained that the intensity of red color was 6.9 and the yellow one was 6.1 , the level of FFA was $2.13 \%$ and its peroxide value was $5.45 \mathrm{meq} / \mathrm{kg}$.

\section{REFERENCES}

Alemdaroglu T.,2003. Investigation of the Surface acidity of a Bentonite Modified by Acid Activation and Thermal Treatment, Turk J Chem Vol.2, p.675 - 681

Ejikeme E.M., Egbuna S.O., Ejikeme P.C.N. , 2013. Optimal Bleaching Performane of Acid Activated Ngwulangwu Clay, International Journal of Engineering and Innovative Technology (IJEIT) Vol.3, Issue 5, p.13-19

Falaras P., Lezou F.,Seiragakis G. and Dimitrios P., 2000. Bleaching Properties Of Alumina-Pillared Acid - ctivated Montmorillonite, Clays and Clay Minerals, Vol.48, No.5, p.549-556

Foletto E. L., Colazzo G. C., Volzone C. and Porto L. M. ,2011. Sunflower Oil Bleaching By Adsor tion Onto AcidActivated Bentonite, Brazilian Journal of Chemical Engineering, Vol. 28, No. 01, p. 169 -174

Fu Y., Chung D.D.L., 2011. Coagulation of oil in water using sawdust, bentonite and calcium hydroxide to form floating sheets, Applied Clay Science 53,p. 634-641

Khan I.H., Tabasum F., Iqbal S., 2014. Utilization Of Locally Available Bentonites For Water Purification By Activation, A scientific journal of Comsats - Science Vision, Vol.20, No.1, p. 67-73
Kurum S.,Akkoca D.B.,2009. The Petrographic Properties of the Epiclastites in Neogen Volcanic Succession and Usage as Admixture in Pozzolanic Cement Production (Cemisgezek/Tunceli,Turkey), Ozean Journa 1 of Applied Sciences 2(1), p.91-101

Makhoukhi B.,Didi M. A., Villeminb D. and Azzouzc A., 2009. Acid Activation of Bentonite For Use as a Vegetable Oil Bleaching Agent, Grasas Y Aceites, 60 (4), Julio-Septiembre, p. 343-349

Usman M.A., Oribayo O., Adebayo A. A.,2013. Bleaching of Palm Oil by Activated Local Bentonite and Kaolin Clay from Afashio Edo - Nigeria, Chemical and Process Engineering Research, Vol.10, p.1-11

Wannahari. R.,Nordin.M.F.N.,2012.Reduction of Peroxide Value in Used Palm Cooking Oil Using Bagasse Adsor bent, American International Journal of Contemporary Research, Vol.2, No.1, p.185-191 